\title{
THE IMPACT OF FORMAL AND INFORMAL INSTITUTIONAL DISTANCES ON MNE CORPORATE SOCIAL PERFORMANCE
}

\author{
Authors \\ Dawn L. Keig* \\ School of Business \\ Whitworth University \\ 300 W Hawthorne Road \\ Spokane, WA 99251 USA \\ Phone: 1-678-230-7241 \\ Email: dkeig@whitworth.edu \\ Lance Eliot Brouthers \\ Department of Management and Entrepreneurship \\ Coles College of Business \\ Kennesaw State University \\ 1000 Chastain Rd NW \\ Kennesaw, GA 30144 USA \\ Phone: 1-770-423-6972 \\ Email: lbrouthe@kennesaw.edu \\ Victor B. Marshall \\ Department of Management and Entrepreneurship \\ Coles College of Business \\ Kennesaw State University \\ 1000 Chastain Rd NW \\ Kennesaw, GA 30144 USA \\ Phone: 1-770-423-6584 \\ Email:vmarsha6@kennesaw.edu
}

*Corresponding author 


\title{
THE IMPACT OF FORMAL AND INFORMAL INSTITUTIONAL DISTANCES ON MNE CORPORATE SOCIAL PERFORMANCE
}

\begin{abstract}
Does country selection affect the corporate social performance (CSP) of multinational enterprises (MNEs)? In this study we suggest that greater institutional diversity within an MNE's operating environment may adversely affect its ability to maintain higher levels of CSP. Using institutional distance and organizational learning as our theoretical lenses, we investigate the impact of institutional differences on CSP. We conceptualize the MNE as a unique portfolio of locations and use the MNE's entire operating footprint to explore the effects of average portfolio formal and informal institutional distances on CSP. We hypothesize and find that firms with greater average informal institutional distance within their portfolios have lower overall levels of CSP. Findings also confirm the moderating influence of formal institutional distance; greater formal institutional distance within the MNE portfolio reduces the CSP benefits of international scope.
\end{abstract}

Keywords: multinational enterprise (MNE); institutional theory; institutional distance; institutional environment; corporate social performance; corporate social responsibility 